\title{
Daylight-White-Emitting and Abnormal Thermal Antiquenching Phosphors Based on a Layered Host $\operatorname{SrIn}_{2}\left(\mathrm{P}_{2} \mathrm{O}_{7}\right)_{2}$
}

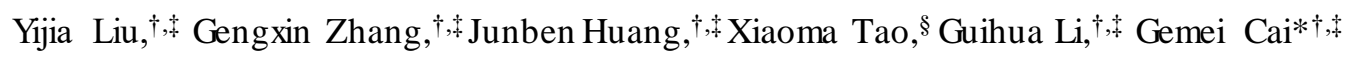

${ }^{\dagger}$ School of Materials Science and Engineering, Central South University, Changsha 410083, Hunan, Peoples R China

Key Lab of Non-Ferrous Metal Materials Science and Engineering, Ministry of Education, Central South University, Changsha 410083, Peoples R China

${ }^{\S}$ College of Physical Science and Technology, Guangxi University, Nanning 530004, Peoples R China

* E-mail: caigemei@csu.edu.cn 
Table S1 Atomic parameters for SIP.

\begin{tabular}{llllllll}
\hline Atom & $\boldsymbol{x} / \boldsymbol{a}$ & $\boldsymbol{y} \boldsymbol{b}$ & $\boldsymbol{z} / \boldsymbol{c}$ & $\boldsymbol{U}$ iso & Occ. & $\boldsymbol{W y c k}$ & C.N. \\
\hline In1 & $0.6175(10)$ & $0.2941(3)$ & $0.1187(17)$ & $0.0015(7)$ & 1 & $8 \mathrm{f}$ & 6 \\
Sr1 & 0.5 & $0.2206(6)$ & -0.25 & $0.0050(11)$ & 1 & $4 \mathrm{e}$ & 10 \\
P1 & $0.5817(2)$ & $0.7011(6)$ & $-0.0775(3)$ & $0.0140(2)$ & 1 & $8 \mathrm{f}$ & 4 \\
P2 & $0.8219(2)$ & $0.4666(5)$ & $0.1390(4)$ & 0.0063 & 1 & $8 \mathrm{f}$ & 4 \\
O1 & $0.5712(7)$ & $0.5887(16)$ & $0.0501(7)$ & 0.0063 & 1 & $8 \mathrm{f}$ & 3 \\
O2 & $0.7330(3)$ & $0.4344(17)$ & $0.1406(14)$ & $0.0100(5)$ & 1 & $8 \mathrm{f}$ & 2 \\
O3 & $0.6293(6)$ & $0.1950(15)$ & $-0.0799(11)$ & 0.0063 & 1 & $8 \mathrm{f}$ & 3 \\
O4 & $0.5077(5)$ & $0.8349(17)$ & $-0.1072(14)$ & $0.0370(6)$ & 1 & $8 \mathrm{f}$ & 3 \\
O5 & $0.6435(7)$ & $-0.0068(17)$ & $0.2257(6)$ & 0.0063 & 1 & $8 \mathrm{f}$ & 3 \\
O6 & $0.8419(4)$ & $0.6626(11)$ & $0.0667(9)$ & 0.0063 & 1 & $8 \mathrm{f}$ & 2 \\
O7 & $0.5932(7)$ & $0.4336(17)$ & $0.3044(9)$ & $0.0120(5)$ & 1 & $8 \mathrm{f}$ & 3 \\
\hline
\end{tabular}


Table S2 Bond lengths ( $(\AA)$ and bond angles $\left(^{\circ}\right)$ in SIP.

\begin{tabular}{|c|c|c|c|c|c|c|c|}
\hline Atom 1 & Atom 2 & Symmetry code & Bond lengths & Atom 1 & Atom 2 & Symmetry code & Bond lengths \\
\hline \multirow[t]{10}{*}{$\operatorname{Sr} 1$} & $\mathrm{O} 3$ & $\mathrm{x}, \mathrm{y}, \mathrm{z}$ & $2.678(102)$ & In 1 & $\mathrm{O} 2$ & $\mathrm{x}, \mathrm{y}, \mathrm{z}$ & $2.108(69)$ \\
\hline & & $1-x, y,-0.5-z$ & & & $\mathrm{O} 7$ & $\mathrm{x}, \mathrm{y}, \mathrm{z}$ & $2.132(112)$ \\
\hline & $\mathrm{O} 1$ & $1-x, 1-y,-z$ & $2.686(92)$ & & O3 & $\mathrm{x}, \mathrm{y}, \mathrm{z}$ & $2.143(99)$ \\
\hline & & $\mathrm{x}, 1-\mathrm{y},-0.5+\mathrm{z}$ & & & $\mathrm{O} 4$ & $1-\mathrm{x}, 1-\mathrm{y},-\mathrm{z}$ & $2.182(105)$ \\
\hline & O5 & $1-x,-y,-z$ & $2.753(115)$ & & $\mathrm{O} 1$ & $\mathrm{x}, \mathrm{y}, \mathrm{z}$ & $2.210(88)$ \\
\hline & & $x,-y,-0.5+z$ & & & O5 & $\mathrm{x}, \mathrm{y}, \mathrm{z}$ & $2.288(104)$ \\
\hline & $\mathrm{O} 7$ & $1-x, 1-y,-z$ & $2.780(116)$ & & & & \\
\hline & & $x, 1-y,-0.5+z$ & & & & & \\
\hline & O4 & $\mathrm{x},-1+\mathrm{y}, \mathrm{z}$ & $2.920(125)$ & & & & \\
\hline & & $1-x,-1+y,-0.5-z$ & & & & & \\
\hline \multirow[t]{4}{*}{ P 1} & $\mathrm{O} 1$ & $\mathrm{x}, \mathrm{y}, \mathrm{z}$ & $1.505(88)$ & $\mathrm{P} 2$ & $\mathrm{O} 2$ & $\mathrm{x}, \mathrm{y}, \mathrm{z}$ & $1.469(61)$ \\
\hline & $\mathrm{O} 7$ & $x, 1-y,-0.5+z$ & $1.506(105)$ & & $\mathrm{O} 3$ & $1.5-x, 0.5-y,-z$ & $1.469(108)$ \\
\hline & $\mathrm{O} 4$ & $\mathrm{x}, \mathrm{y}, \mathrm{z}$ & $1.516(101)$ & & O5 & $1.5-x, 0.5+y, 0.5-z$ & $1.473(80)$ \\
\hline & O6 & $1.5-x, 1.5-y,-z$ & $1.537(76)$ & & O6 & $\mathrm{x}, \mathrm{y}, \mathrm{z}$ & $1.524(85)$ \\
\hline \multicolumn{2}{|l|}{ Bond } & \multicolumn{2}{|l|}{ Bond angles } & \multicolumn{2}{|l|}{ Bond } & \multicolumn{2}{|c|}{ Bond angles } \\
\hline \multicolumn{2}{|l|}{ O7-P1-O1 } & \multicolumn{2}{|l|}{$114.6(490)$} & \multicolumn{2}{|c|}{$\mathrm{O} 3-\mathrm{P} 2-\mathrm{O} 2$} & \multicolumn{2}{|c|}{$116.9(499)$} \\
\hline \multicolumn{2}{|l|}{ O7-P1-O4 } & \multicolumn{2}{|l|}{$117.9(648)$} & \multicolumn{2}{|c|}{$\mathrm{O} 3-\mathrm{P} 2-\mathrm{O} 5$} & \multicolumn{2}{|c|}{$105.7(583)$} \\
\hline \multicolumn{2}{|l|}{ O7-P1-O6 } & \multicolumn{2}{|l|}{$105.8(560)$} & \multicolumn{2}{|c|}{$\mathrm{O} 3-\mathrm{P} 2-\mathrm{O} 6$} & \multicolumn{2}{|c|}{$106.6(514)$} \\
\hline \multicolumn{2}{|l|}{ O1-P1-O4 } & \multicolumn{2}{|l|}{$109.8(645)$} & \multicolumn{2}{|c|}{$\mathrm{O} 2-\mathrm{P} 2-\mathrm{O} 5$} & \multicolumn{2}{|c|}{$110.5(550)$} \\
\hline \multicolumn{2}{|l|}{ O1-P1-O6 } & $110.2(547)$ & & $\mathrm{O} 2-\mathrm{P} 2-$ & & $111.0(4$ & 51) \\
\hline O4-P1-O6 & & $108.4(452)$ & & O5-P2- & & $105.4(5$ & 7) \\
\hline
\end{tabular}


Table S3 IR band information $\left(\mathrm{cm}^{-1}\right)$ of SIP.

\begin{tabular}{lll}
\hline Frequency & Peak positions $\left(\mathbf{c m}^{-\mathbf{1}}\right)$ & Assignment \\
\hline low frequency & $487.0 \mathrm{~cm}^{-1}$ & $(\gamma)$ of O-P-O \\
& $516.0-634.0 \mathrm{~cm}^{-1}$ & $(\delta)$ of O-P-O \\
intermediate frequency & $765.0 \mathrm{~cm}^{-1}$ & $\left(v_{s}\right)$ of P-O-P \\
& $931.4 \mathrm{~cm}^{-1}$ & $\left(v_{a s}\right)$ of P-O-P \\
high frequency & $1006.7 \mathrm{~cm}^{-1} 、 1037.1 \mathrm{~cm}^{-1}$ & $\left(v_{s}\right)$ of O-P-O \\
& $1068.4 \mathrm{~cm}^{-1} 、 1108.0 \mathrm{~cm}^{-1}$ & $\left(v_{a s}\right)$ of O-P-O \\
\hline
\end{tabular}


Table S4 Experimental parameters of powder X-ray diffraction, crystallographic data, and reliability factors of Rietveld refinement for SIP: $\mathrm{RE}^{3+}$ phosphors.

\begin{tabular}{|c|c|c|c|}
\hline Sample & SIP: $0.02 \mathrm{Tm}^{3+}$ & SIP: $0.02 \mathrm{Dy}^{3+}$ & SIP: $0.01 \mathrm{Tm}^{3+}, 0.01 \mathrm{Dy}^{3+}$ \\
\hline Radiation type & $\mathrm{Cu} K \alpha$ & $\mathrm{Cu} K \alpha$ & $\mathrm{Cu} K \alpha$ \\
\hline Monochromator & Graphite & Graphite & Graphite \\
\hline Wavelength $(\AA)$ for Ka1 & 1.5406 & 1.5406 & 1.5406 \\
\hline Refined Profile range $2 \theta\left(^{\circ}\right)$ & $5-130^{\circ}$ & $5-130^{\circ}$ & $5-130^{\circ}$ \\
\hline Step size $2 \theta\left(^{\circ}\right)$ & 0.017 & 0.017 & 0.017 \\
\hline Step scan time per step (s) & 2 & 2 & 2 \\
\hline$R_{B}(\%)$ & 4.82 & 3.96 & 4.49 \\
\hline$R_{p}(\%)$ & 2.90 & 3.26 & 2.68 \\
\hline$R_{w p}(\%)$ & 3.76 & 4.42 & 3.53 \\
\hline$S$ & 1.56 & 1.72 & 1.55 \\
\hline Symmetry & Monoclinic & Monoclinic & Monoclinic \\
\hline Space group & $C 2 / c$ & $C 2 / c$ & $C 2 / c$ \\
\hline$a(\AA)$ & $16.3446(2)$ & $16.3458(2)$ & $16.3448(2)$ \\
\hline$b(\AA)$ & $6.5768(1)$ & $6.5768(1)$ & $6.5766(1)$ \\
\hline$c(\AA)$ & $10.1325(1)$ & $10.1340(1)$ & $10.1328(1)$ \\
\hline$\beta\left(\left(^{\circ}\right)\right.$ & $92.265(9)$ & $92.262(8)$ & $92.266(8)$ \\
\hline$V\left(\AA^{3}\right)$ & 1088.21(3) & $1088.58(2)$ & $1088.36(2)$ \\
\hline$Z$ & 4 & 4 & 4 \\
\hline Calculated density $\left(\mathrm{g} / \mathrm{cm}^{-3}\right)$ & 4.154 & 4.155 & 4.155 \\
\hline
\end{tabular}




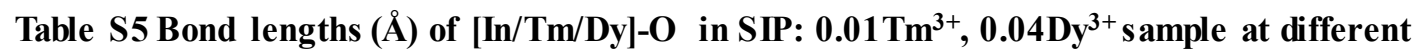
temperature.

\begin{tabular}{|c|c|c|c|c|c|c|c|}
\hline & $297 \mathrm{~K}$ & $323 \mathrm{~K}$ & $373 \mathrm{~K}$ & $423 \mathrm{~K}$ & $473 \mathrm{~K}$ & $523 \mathrm{~K}$ & $573 \mathrm{~K}$ \\
\hline$[\mathbf{I n} / \mathbf{T m} / \mathbf{D y}]-\mathbf{O} 1$ & $2.2872(200)$ & $2.2019(142)$ & $2.2090(142)$ & $2.2408(144)$ & $2.2204(196)$ & $2.2292(140)$ & $2.2260(168)$ \\
\hline$[\operatorname{In} / \mathbf{T m} / \mathrm{Dy}]-\mathrm{O} 2$ & $2.2384(210)$ & $2.1833(185)$ & $2.1778(172)$ & $2.2142(186)$ & $2.2062(185)$ & $2.2263(157)$ & $2.2251(196)$ \\
\hline$[\mathbf{I n} / \mathbf{T m} / \mathrm{Dy}]-\mathbf{O} 3$ & $2.1348(196)$ & $2.2121(176)$ & $2.1610(176)$ & $2.1827(167)$ & $2.1912(176)$ & $2.2166(149)$ & $2.1794(185)$ \\
\hline$[\operatorname{In} / \mathbf{T m} / \mathrm{Dy}]-\mathrm{O} 4$ & $2.3043(197)$ & $2.3506(146)$ & $2.2969(147)$ & $2.3352(147)$ & $2.3455(161)$ & $2.3582(146)$ & $2.3344(143)$ \\
\hline$[\mathbf{I n} / \mathbf{T m} / \mathrm{Dy}]-05$ & $2.2721(200)$ & $2.2962(149)$ & $2.3461(146)$ & $2.2907(146)$ & $2.2874(147)$ & $2.2751(142)$ & $2.3040(148)$ \\
\hline$[\mathbf{I n} / \mathbf{T m} / \mathbf{D y}]-07$ & $2.1125(205)$ & $2.1256(196)$ & $2.1942(195)$ & $.1296(196)$ & $2.1603(203)$ & $2.1298(167)$ & $2.1883(147)$ \\
\hline$d a v$ & 2.2249 & 2.2283 & 2.2308 & 2.2322 & 2.2352 & 2.2392 & 2.2429 \\
\hline
\end{tabular}




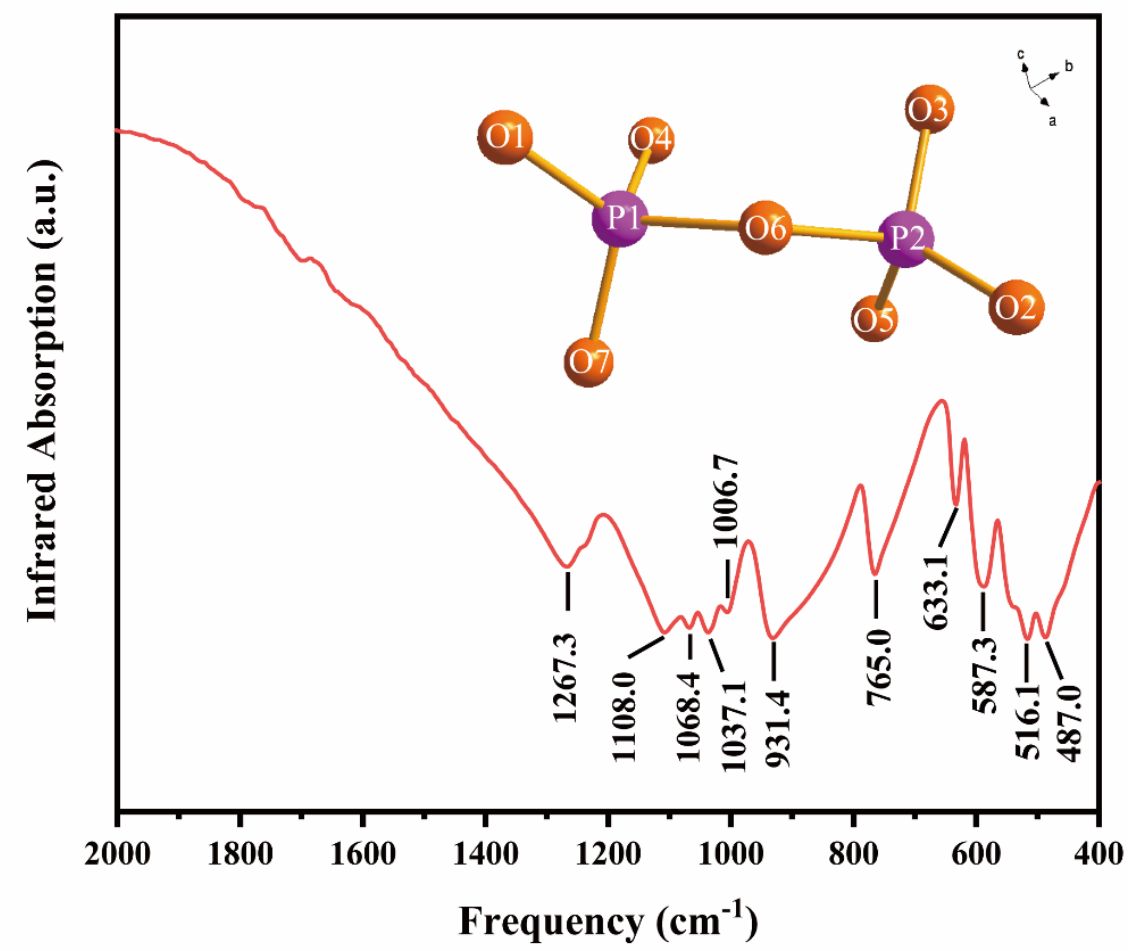

Fig. S1 IR spectra for powder SIP sample. Inset shows the corner-sharing $\mathrm{P}_{2} \mathrm{O}_{7}$ groups. 

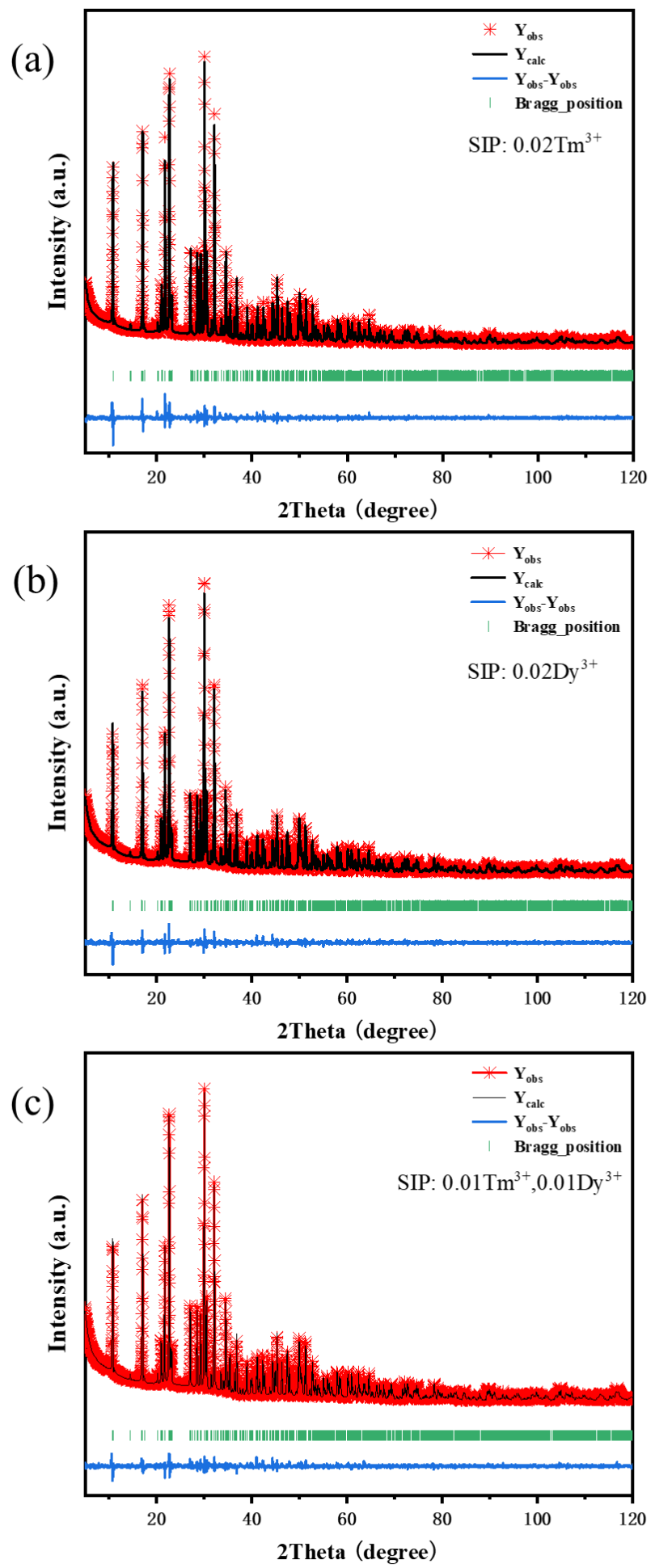

Fig. S2 Rietveld refinement patterns for (a) SIP: $0.02 \mathrm{Tm}^{3+}$, (b) SIP: $0.02 \mathrm{Dy}^{3+}$, and (c) SIP: $0.01 \mathrm{Tm}^{3+}$, $0.01 \mathrm{Dy}^{3+}$. 


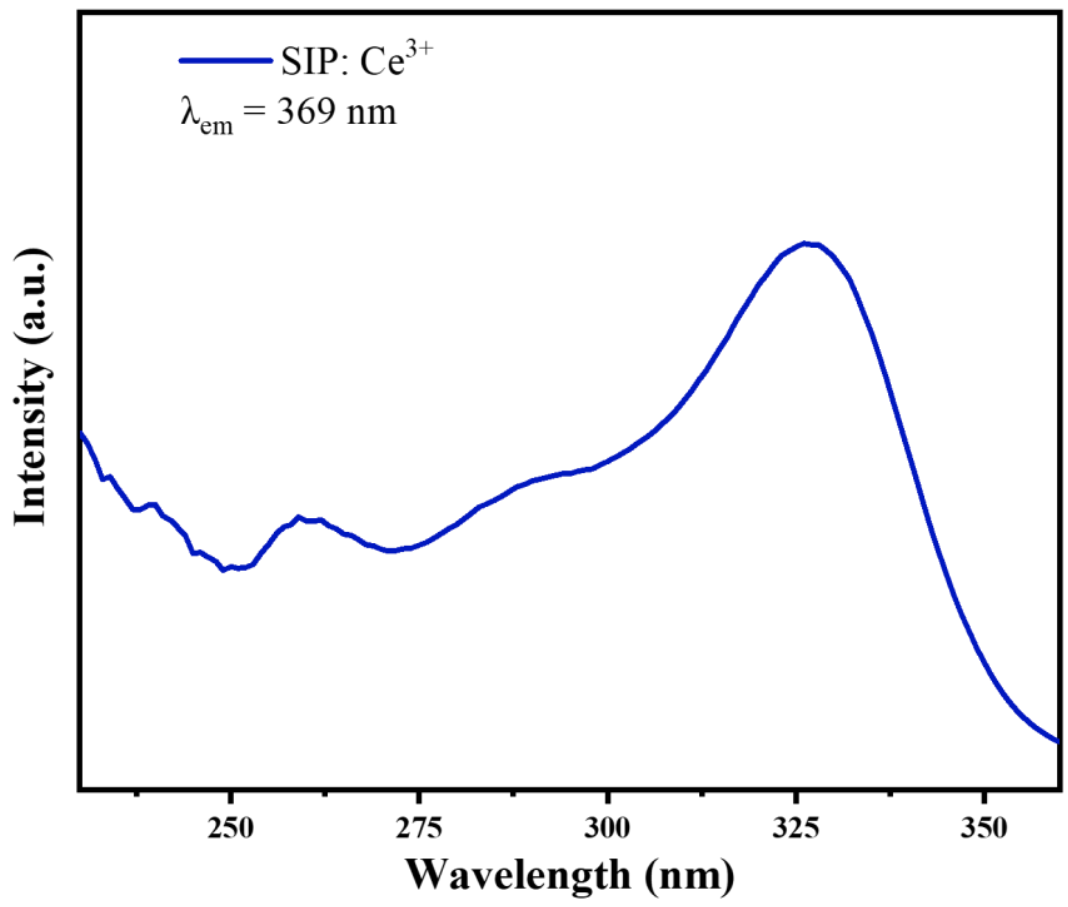

Fig. S3 Photoluminescence excitation spectra of SIP: $\mathrm{Ce}^{3+}$ sample. 


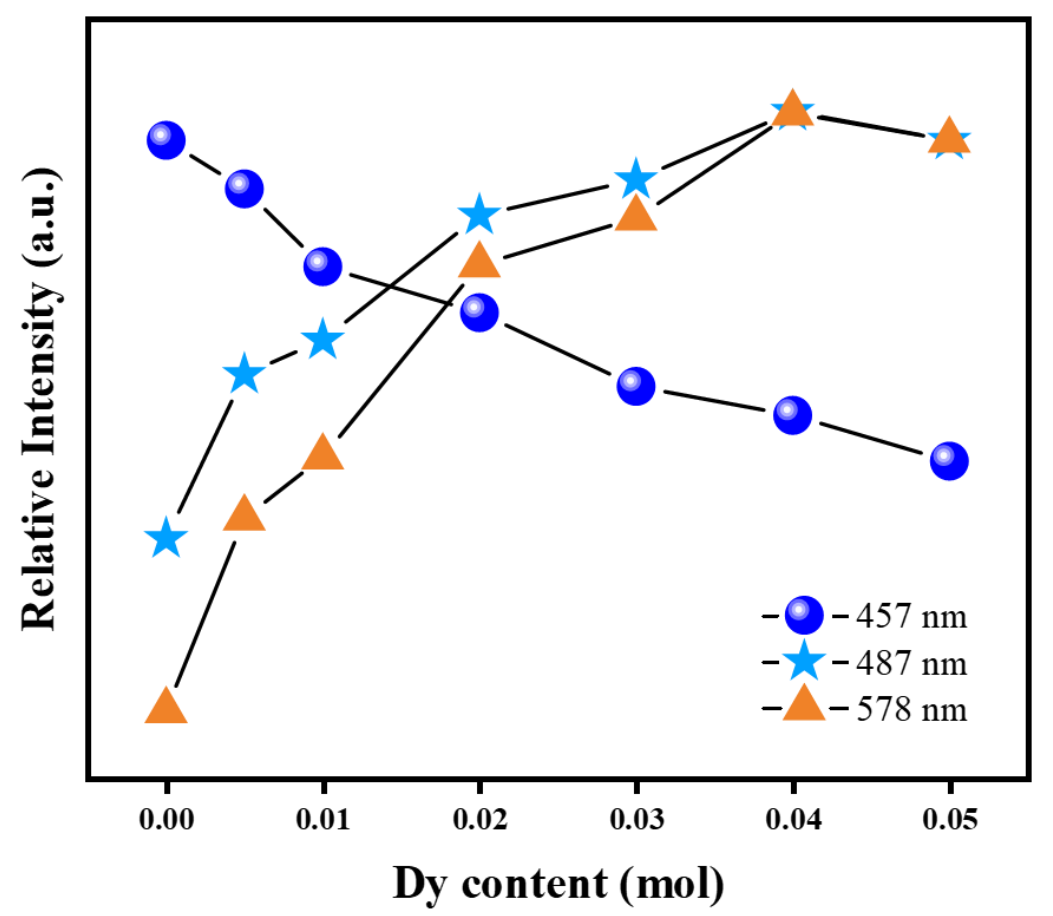

Fig. S5 Dependence of emission intensities peaking at $457 \mathrm{~nm}, 487 \mathrm{~nm}$ and $573 \mathrm{~nm}$ on $\mathrm{Dy}^{3+}$ concentration. 


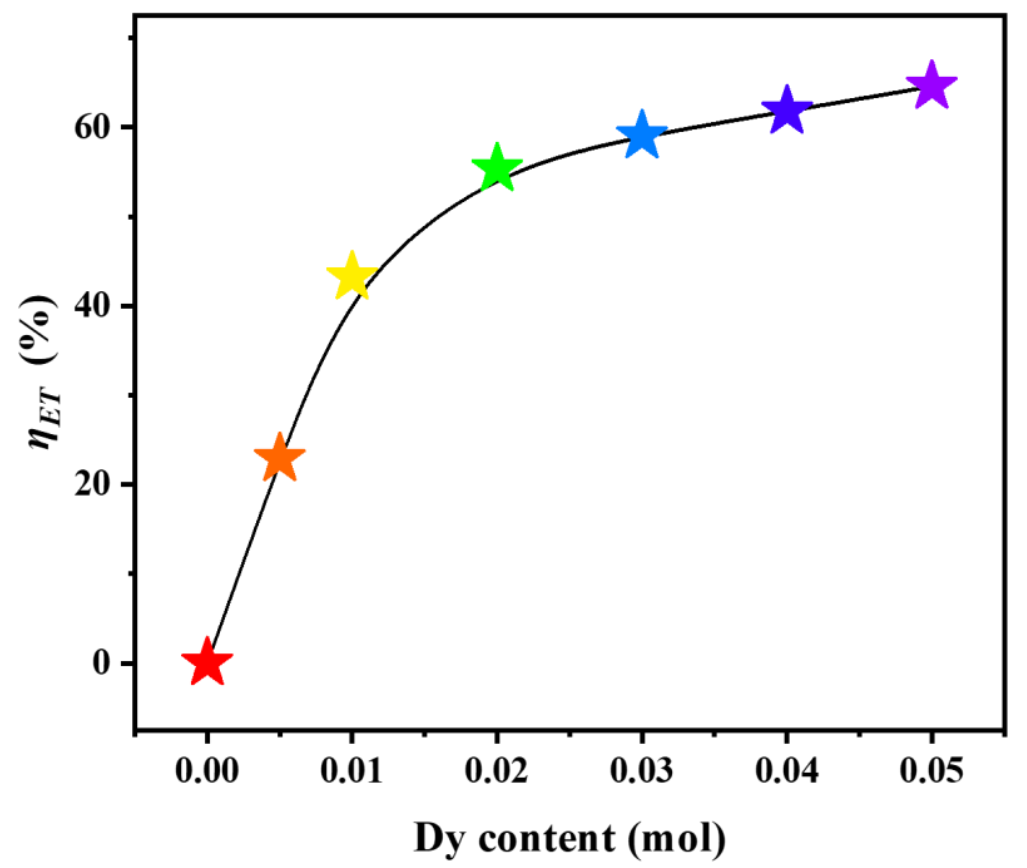

Fig. S5 Energy transfer efficiencies $\left(\eta_{E T}\right)$ of SIP: $0.02 \mathrm{Tm}^{3+}, \mathrm{yDy}^{3+}$ as a function of $\mathrm{Dy}^{3+}$ concentrations. 


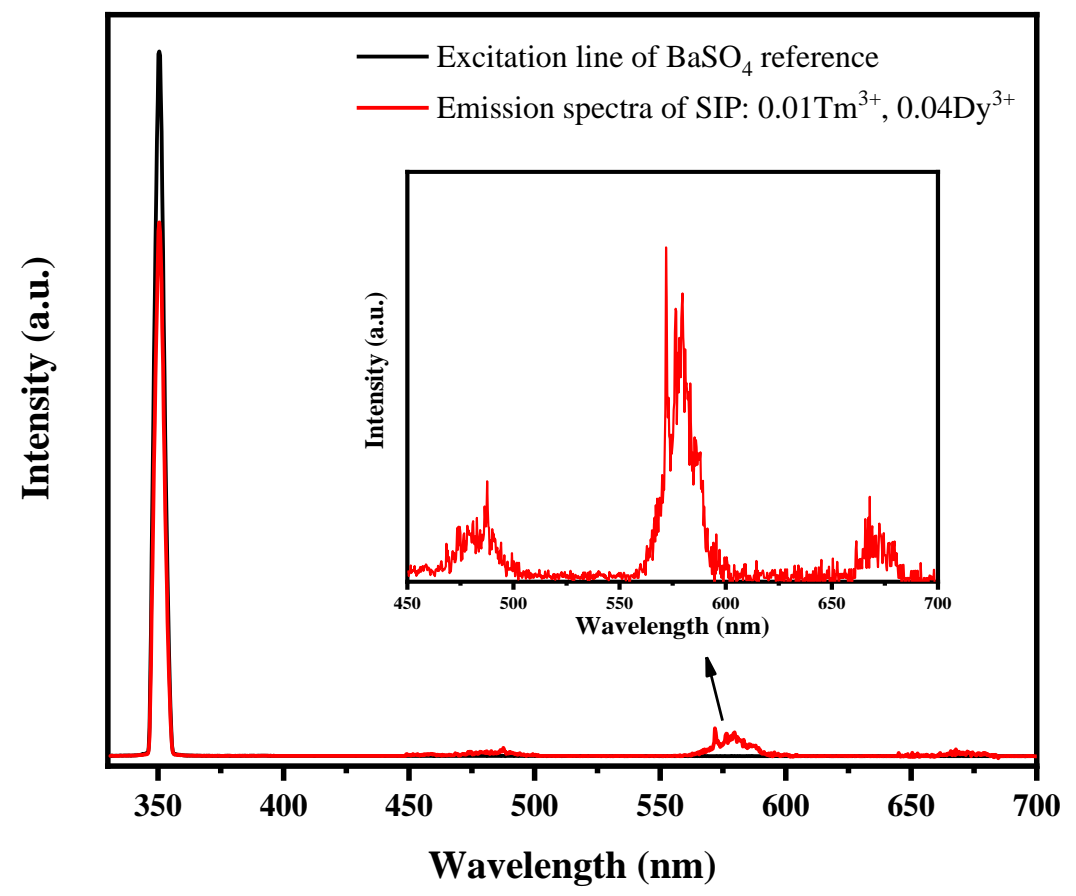

Fig. S6 The excitation line of $\mathrm{BaSO}_{4}$ and the emission spectrum of SIP: $0.01 \mathrm{Tm}^{3+}, 0.04 \mathrm{Dy}^{3+}$ phosphor collected using an integrating sphere. Inset shows a magnification of the emission spectrumfrom $450 \mathrm{~nm}$ to $700 \mathrm{~nm}$. 


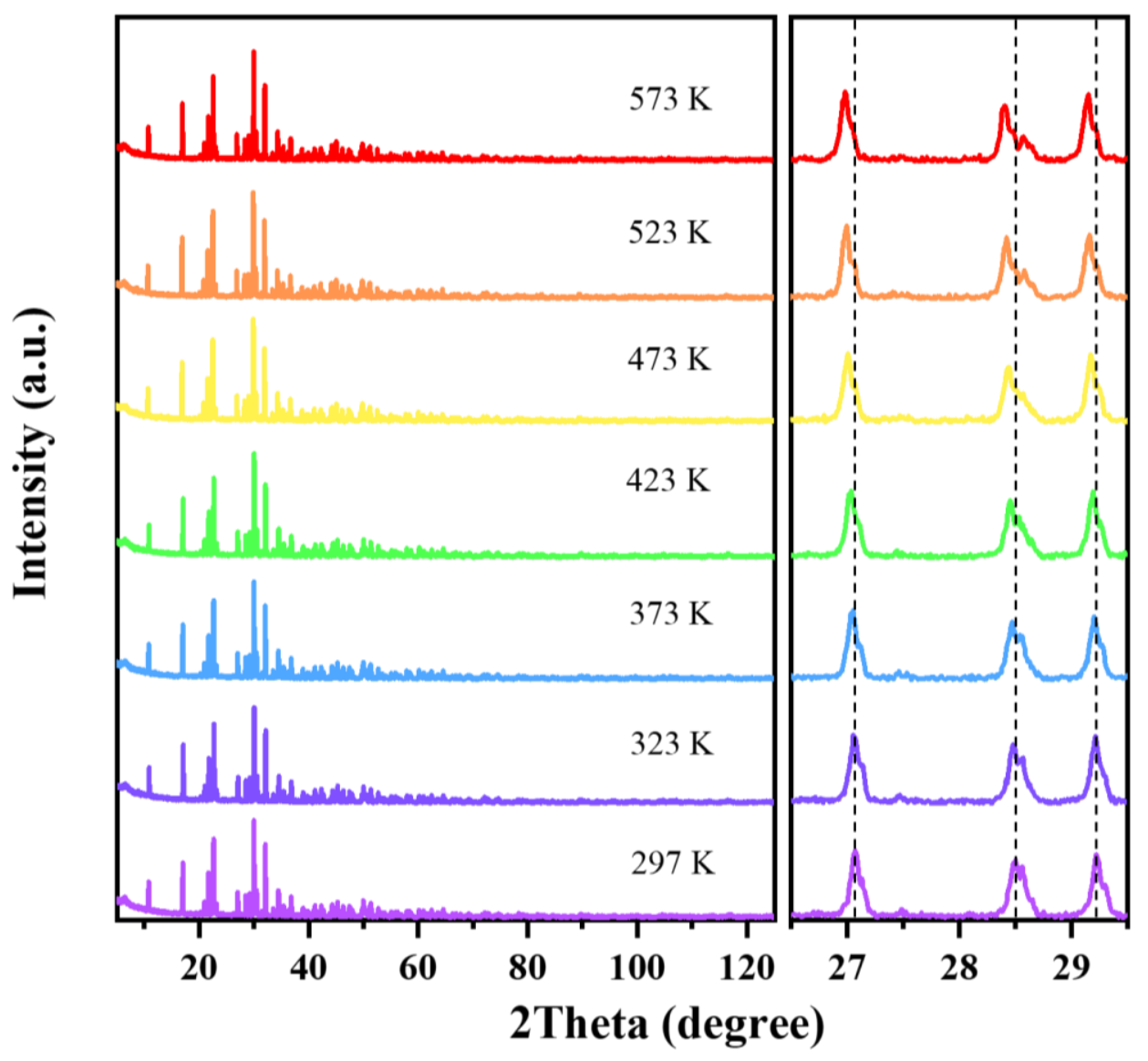

Fig. S7 Powder XRD patterns for SIP: $0.01 \mathrm{Tm}^{3+}, 0.04 \mathrm{Dy}^{3+}$ phos phor at different temperatures . 

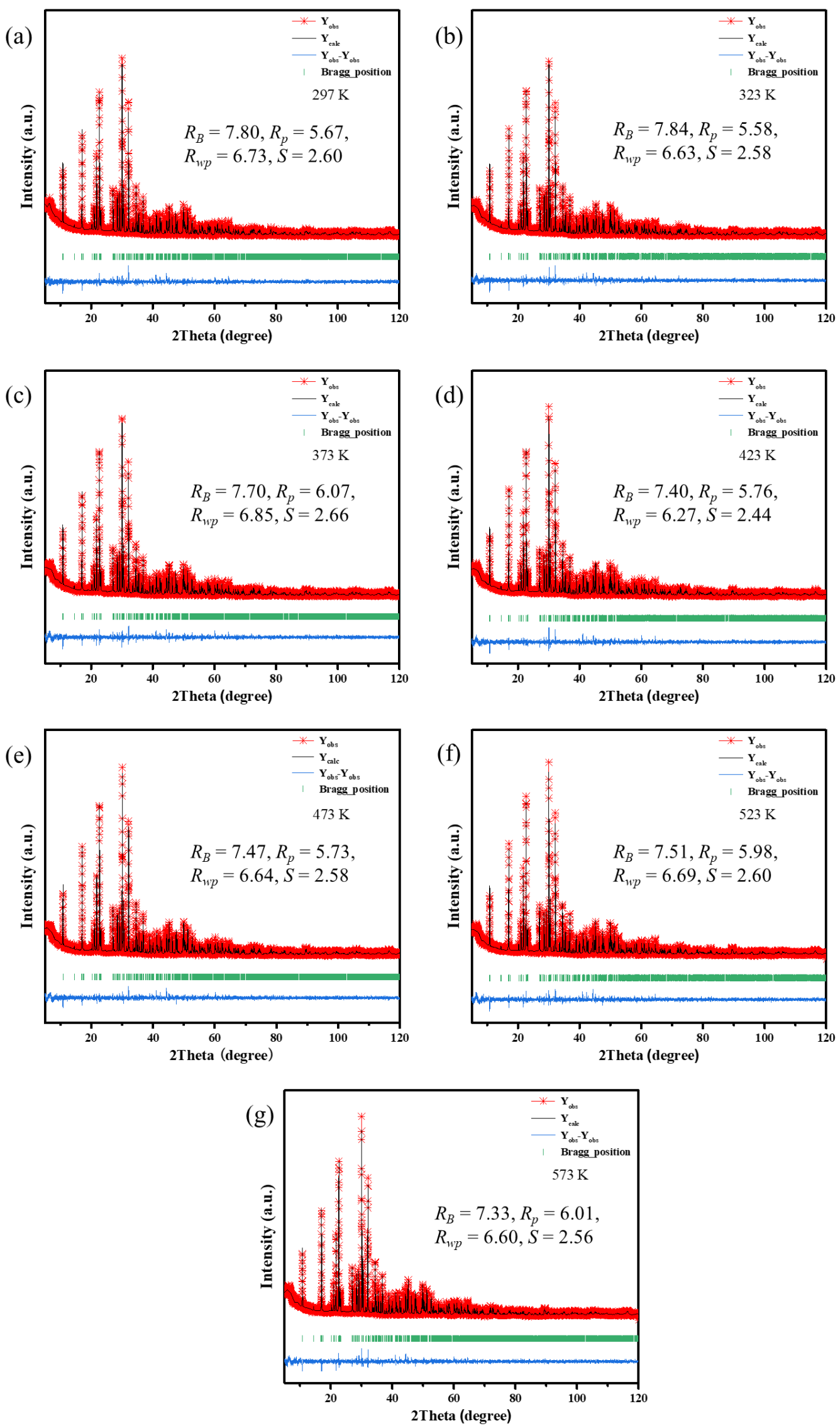

Fig. S8 Rietveld refinement patterns for SIP: $0.01 \mathrm{Tm}^{3+}, 0.04 \mathrm{Dy}^{3+}$ phos phor at different temperature: (a) $297 \mathrm{~K}$, (b) $323 \mathrm{~K}$, (c) $373 \mathrm{~K}$, (d) $423 \mathrm{~K}$, (e) $473 \mathrm{~K}$, (f) $523 \mathrm{~K}$ and (g) $573 \mathrm{~K}$. 

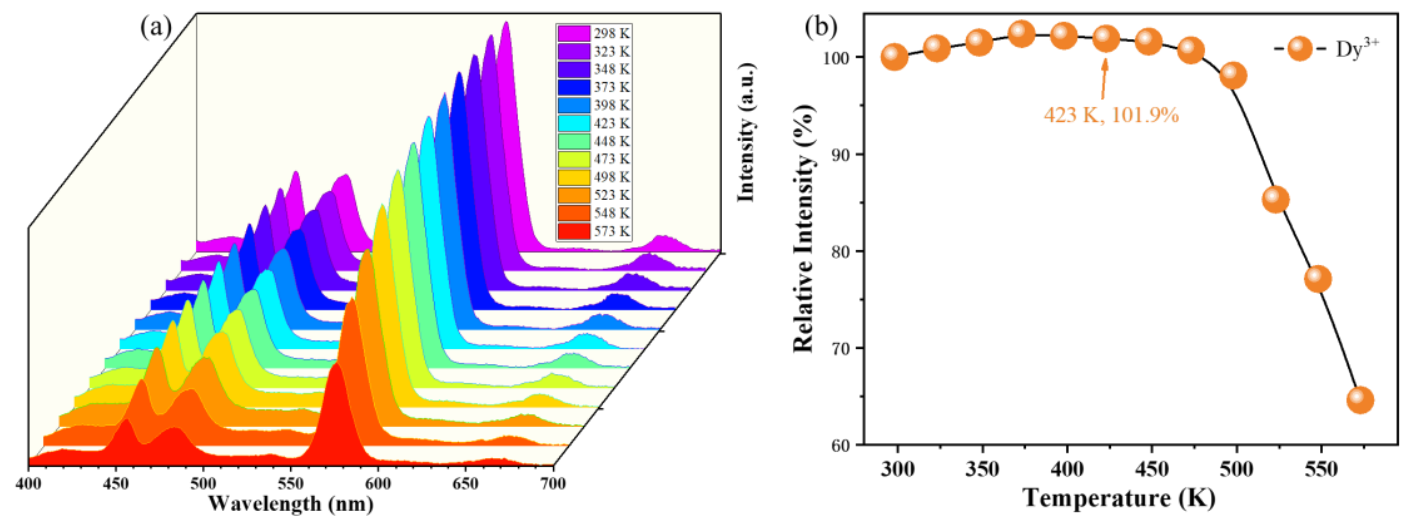

Fig. S9 (a) Temperature dependence emis sion spectra of SIP: $0.02 \mathrm{Tm}^{3+}, 0.04 \mathrm{Dy}^{3+}$ phos phor excited at $351 \mathrm{~nm}$. (b) Dependence of integral emission intensity on test temperatures. 
Formula S1 The calculation expression of interaction type between sensitizers or between sensitizer and activator proposed by Dexter and Van Uitert.

$$
\frac{I}{x}=k\left[1+\beta(x)^{\frac{\theta}{3}}\right]^{-1},
$$

where $I$ and $x$ represent the emission intensity and activator dopant concentration, and $\beta$ and $k$ are constants. The value of $\theta$ is the type of interaction, and when $\theta=$ 6,8 , or 10 , respectively, it corresponds to the dipole-dipole (d-d), dipole-quadrupole (d-q), or quadrupole-quadrupole (q-q) interaction.

Formula S2: Jørgensen empirical equation.

$$
E_{C T}=\left[\chi_{\text {opt }}(X)-\chi_{\text {opt }}(M)\right] \times 30 \times 10^{3}
$$

$\mathrm{cm}^{-1}$

here, $E_{C T}$ is the energy of CTB, $\chi_{\text {opt }}(X)$ and $\chi_{\text {opt }}(M)$ stand for the optical electronegativities of the anion $X$ and central cation $M$.

Formula S3 The calculation expression of the position of $f-d$ transition for $\mathrm{REs}^{3+}$.

$$
E(\mathrm{Ln}, \mathrm{A})=E(\mathrm{Ce}, \text { free })-D(\mathrm{~A})+\Delta E^{\mathrm{Ln}, \mathrm{Ce}},
$$

where $E(\mathrm{Ln}, \mathrm{A})$ is the energy of the $f-d$ transition of the REs $\mathrm{Ln}^{3+}$ in compound $\mathrm{A}, E(\mathrm{Ce}$, free), which has been determined to be $49,340 \mathrm{~cm}^{-1}$, is the energy of is the energy of the free $\mathrm{Ce}^{3+} f-d$ transition. $D(\mathrm{~A})$ is the reduction of the $5 d$ energy of $\mathrm{Ln}^{3+}$ in compound $\mathrm{A}$ compared to $\mathrm{Ce}^{3+}, \Delta E^{\mathrm{Ln}, \mathrm{Ce}}$ is the average value of the $f$ - $d$ transition energy differences of $\mathrm{Ln}^{3+}$ and $\mathrm{Ce}^{3+}$.

Formula S4 The second-order exponential decay equation.

$$
I(t)=A_{1} \exp \left(-\frac{t}{\tau_{1}}\right)+A_{2} \exp \left(-\frac{t}{\tau_{2}}\right)
$$

$I(t)$ is the luminescence intensity at time $t, A_{1}$ and $A_{2}$ represent the corresponding fitting parameters, $\tau_{1}$ and $\tau_{2}$ stand for the fitted rapid and slow components of decay lifetime, respectively. 
Formula S5 The calculation expression of internal quantum efficiency.

$$
\eta_{Q E}=\frac{\int L_{S}}{\int E_{R}-\int E_{S}},
$$

where $L_{S}$ represents the emission spectra of the sample, $E_{S}$ and $E_{R}$ stand for the excitation spectra with and without the sample in the integrating sphere. 